\title{
Regional Warming and Emerging Vector-Borne Zoonotic Dirofilariosis in the Russian Federation, Ukraine, and Other Post-Soviet States from 1981 to 2011 and Projection by 2030
}

\author{
Vladimir Kartashev, ${ }^{1}$ Alexandr Afonin, ${ }^{2}$ Javier González-Miguel, ${ }^{3}$ Rosa Sepúlveda, \\ Luis Simón, ${ }^{3}$ Rodrigo Morchón, ${ }^{3}$ and Fernando Simón ${ }^{3}$ \\ ${ }^{1}$ Department of Infectious Diseases, Rostov State Medical University, Nakhichevanskiy Pereulok 29, Rostov-na-Donu 344022, Russia \\ ${ }^{2}$ Faculty of Geography, Saint Petersburg State University, Universitetskaya Nab. 7-9, Saint Petersburg 199034, Russia \\ ${ }^{3}$ Laboratory of Parasitology, Faculty of Pharmacy \& IBSAL, University of Salamanca, C/del Licenciado Méndez Nieto s/n, \\ 37007 Salamanca, Spain \\ ${ }^{4}$ Department of Statistics, University of Salamanca, C/Alfonso X el Sabio S/N, 37007 Salamanca, Spain
}

Correspondence should be addressed to Fernando Simón; fersimon@usal.es

Received 27 January 2014; Accepted 23 May 2014; Published 19 June 2014

Academic Editor: Nongyao Sawangjaroen

\begin{abstract}
Copyright (C) 2014 Vladimir Kartashev et al. This is an open access article distributed under the Creative Commons Attribution License, which permits unrestricted use, distribution, and reproduction in any medium, provided the original work is properly cited.

We analyze through a climatic model the influence of regional warming on the geographical spreading and potential risk of infection of human dirofilariosis in Russia, Ukraine, and other post-Soviet states from 1981 to 2011 and estimate the situation by 2030. The model correctly predicts the spatiotemporal location of $97.10 \%$ of 2154 clinical cases reported in the area during the studied period, identified by a retrospective review of the literature. There exists also a significant correlation between annual predicted Dirofilaria generations and calculated morbidity. The model states the progressive increase of $14.8 \%$ in the potential transmission area, up to latitude $64^{\circ} \mathrm{N}$, and $14.7 \%$ in population exposure. By 2030 an increase of $18.5 \%$ in transmission area and $10.8 \%$ in population exposure is expected. These findings strongly suggest the influence of global warming in both geographical spreading and increase in the number of Dirofilaria generations. The results should alert about the epidemiological behavior of dirofilariosis and other mosquito-borne diseases in these and other countries with similar climatic characteristics.
\end{abstract}

\section{Introduction}

Climatic change strongly affects human and animal health increasing the risk of infections by many vector-borne parasitic, bacteria, and virus diseases $[1,2]$. The temporal and spatial changes in temperature, rainfall, and humidity influence the distribution and seasonality of vectors and the extrinsic incubation of pathogens [3]. There is currently a considerable concern in the European institutions about the emergence or reemergence in the continent of some mosquito-borne diseases like malaria, leishmaniosis, dirofilariosis, West Nile virus, and chikungunga, among others, as a consequence of the climatic change $[3,4]$.

Dirofilariosis is a zoonotic disease mosaic transmitted by culicid mosquitoes, affecting dogs, cats, and humans, caused mainly by the filarid nematodes D. immitis and D. repens [5]. While animal dirofilariosis may result from a benign to a severe and potentially fatal disease [6], human dirofilariosis manifests itself as benign subcutaneous or pulmonary nodules that mimic malignant tumors [7] caused by immature worms. With increasing frequency in humans, fully developed $D$. repens adult worms are detected in conjunctival, retroocular, and intravitreal locations, responsible for loss of vision or other permanent ocular alterations $[8,9]$. In addition, surgical removal of the nodules, very aggressive in pulmonary and intraocular/retroocular cases, can cause considerable damages and treatment costs $[10,11]$.

In Western Europe dirofilariosis has been historically considered endemic in the Mediterranean countries [12, 13], but during the last 14 years a rapid expansion into central 
and northern countries has occurred, mainly attributed to global warming [9]. In Eastern European countries dirofilariosis also exists but information on the epidemiological situation in canine populations is partial and limited. However, information is relatively abundant on human dirofilariosis, since many of the clinical cases recently reported in the world have been diagnosed in Ukraine and Russia, almost all attributed to $D$. repens $[5,14,15]$. Models to predict diseases patterns have become very valuable tools helping the design of appropriate control strategies $[2,16]$. Unlike in other infectious diseases, in which predictions are difficult to assess $[3,17]$, changes predicted on dirofilariosis in Western Europe [18] were repeatedly confirmed, since its emergence in some central and northern European countries, previously free of dirofilariosis, has been already demonstrated [5]. Thus, dirofilariosis appears as a good model to evaluate the impact of global warming on the spread of mosquito-borne diseases. Furthermore, the influence of the changing climatic factors on the dynamic and trends of dirofilariosis has not been yet analyzed in the European far East, in spite of the strong thermal anomalies recently observed [19] and the recognition of dirofilariosis as an emerging disease $[14,15]$ in some postSoviet states.

In the present work we developed a spatiotemporal geographic information system (GIS) model of Dirofilaria transmission in the former USSR based on the accumulated heat necessary to complete L3 development. Its validation was assessed by the spatial and temporal referentiation of human clinical cases obtained by an exhaustive retrospective review of different sources from 1981 to 2011 and derived morbidity. Moreover, a projection of the situation by 2030 is presented.

\section{Materials and Methods}

2.1. Data. We used daily temperature data recorded by a network of 421 meteorological stations of the Russian Federation and neighboring countries from 1981 to 2011 and temperatures foreseen by 2030 by the Russian Committee of Hydrometeorology [20].

Population data of each administrative unit of the former USSR were obtained from the current Russian State Federal Statistic Committee, State Statistics Committee of Ukraine, and the World Bank web site. Because the whole population appeared stable from 1981 to 2011 with a slight increase of $0.1 \%$, we assumed the population data of 2011 for all calculations.

An exhaustive retrospective review of clinical cases of human dirofilariosis reported in the territory of the former USSR between 1981 and 2011 was carried out with the objective of the spatiotemporal referencing (year and administrative unit of occurrence) of each autochthonous case. The search was made using the following sources: (1) national and local medical journals from Russia and neighboring countries; (2) the archives of the Ukrainian Healthcare Ministry since 1997; (3) PubMed database to corroborate that no cases of human dirofilariosis have been published in nonRussian language journals was also consulted. Cases without date and/or geographical reference were excluded (8 cases).
Clinical cases together with population data were used to calculate morbidity (number of cases/year/100000 people).

2.2. Model. The model predicts the spatiotemporal distribution of the number of generations of infective L3 of Dirofilaria that can yearly develop in the mosquito vectors (directly related to the annual length of the transmission period), considering temperatures calculated as indicated below. Full development of L3 needs 130 growing degree-days (GDDs) [16] accumulated in 30 consecutive days, the estimated mean life expectancy of a mosquito vector. Each day accumulates a number of GDDs resulting from the difference between the mean daily temperature and the threshold temperature for extrinsic incubation of Dirofilaria (L3 development), which has been already experimentally calculated in $14^{\circ} \mathrm{C}[21,22]$. Thus, the mean annual accumulated GDDs were used to calculate the number of annual generations of Dirofilaria developed in the vectors.

A GIS for the area studied was generated using the georeferenced meteostations previously indicated, the former Soviet Union regional administrative boundaries (oblasts and republics), and the model output databases. Given the high correlation between the indexes based on the GDD and altitude and latitude, the map of generations was produced following the methodology previously described [23-25]. In brief, considering the average GDDs previously calculated to each meteostation, for every 10-year period: 1981-1990, 19912000, 2001-2011, and on 2030, regressions were established to calculate the influence of altitude and latitude on GDD.

The GDD matrix was calculated using an image calculator module in accordance with the obtained regression formula, where corresponding latitudinal and altitudinal matrices were used as substitutes for latitude and altitude values. SRTM digital elevation models were used as altitudinal matrices [26]. The difference between calculated and real GDD values was the remainder. It was calculated as the difference between the regression calculated GDD and the real GDD for every meteorological station and interpolated over the whole analyzed territory by linear Kriging procedure. The interpolated remainder's layer was added to the calculated layer. The procedure was separately repeated for the coastal and continental stations. The coastal meteostations were located less than $30 \mathrm{~km}$ to the sea and the continental meteostations were located more than $30 \mathrm{~km}$ to the sea. The calculations were done separately because coastal and continental temperatures have different values and dynamic. After that, the coastal and continental GDD layers were joined through coastal $30 \mathrm{~km}$ buffer. The resulting GDD layers describing situation for 1981-1990, 1991-2000, 20012011, and 2030 have spatial resolution $10 \mathrm{~km}$ and presented in Albers Conic projection.

To validate the model two factors were analyzed: (1) the concordance between the predicted transmission areas and the spatiotemporal distribution of cases obtained by the retrospective review and (2) the statistical correlation between the number of predicted generations of Dirofilaria and the observed morbidity. This statistical correlation was evaluated globally and by decades using the Pearson 


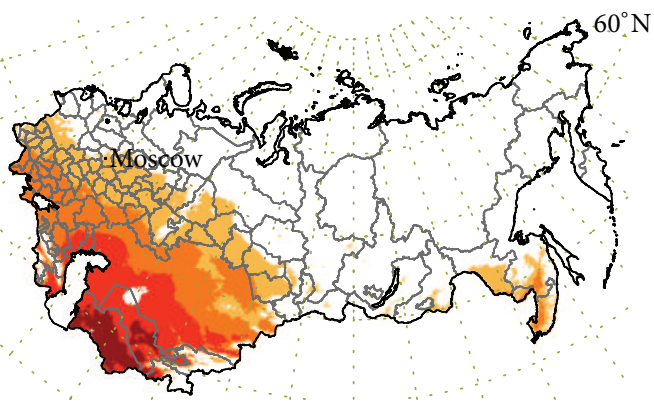

(a)

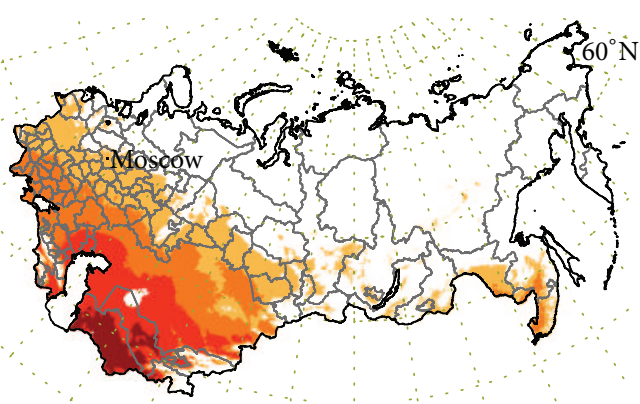

(b)

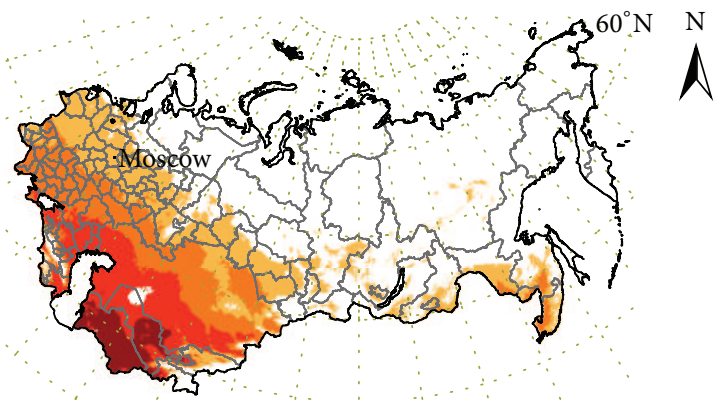

(c)

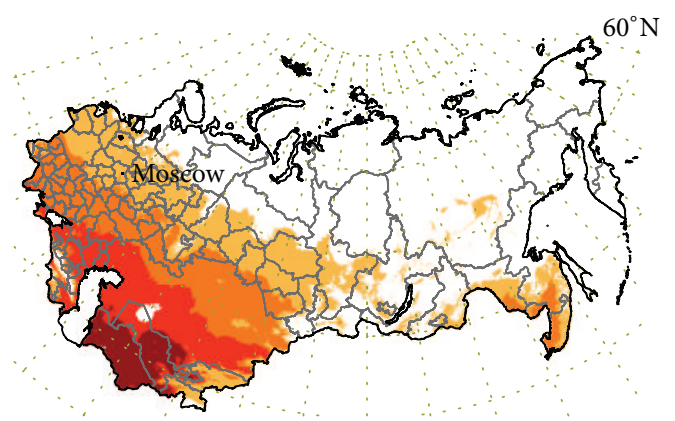

(d)

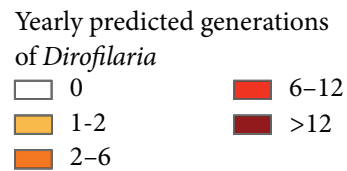

Kilometers

$\begin{array}{lll}0 & 1.400 & 2.800\end{array}$

FIGURE 1: Retrospective prediction model of Dirofilaria transmission in the former USSR. Distribution of annual predicted generations: 1981-1990 (a), 1991-2000 (b), and 2001-2011 (c) and projection of the future scenario by 2030 (d).

correlation analysis, considering a significant correlation when $P<0.01$ (highly significant).

Projection by 2030 scenario predicts the distribution of the transmission areas, including the number of predicted generations of Dirofilaria, and estimates the person-year of exposure using the same methodology described for the retrospective model.

\section{Results}

The model generated retrospectively predicts the existence of two different potential transmission areas of dirofilariosis, one in the South West and other in the Asian Far East of the territory studied, where a different number of annual generations of Dirofilaria exist. Moreover, the model predicts significant changes over time (Figures 1(a), 1(b), and 1(c)). From 1981 to $1990,1 / 3$ of the territory studied becomes a suitable area for transmission. The Southwestern area covered from Ukraine to the Eastern borders of the Asian republics, excluding the Caucasus, Urals, and Tien Shan/Pamir ranges. In the northern part of this area, with the boundary in latitude $53-57^{\circ} \mathrm{N}$ in the European part of the Russian Federation and $61^{\circ} \mathrm{N}$ in Western Siberia, summer temperatures are low, optimal conditions for extrinsic incubation of Dirofilaria appear only sporadically, and 1 to 2 annual generations are predicted. In the Southern side high temperatures allow Dirofilaria extrinsic incubation during long periods each year, including two zones with 6-12 and more than 12 annual predicted generations, respectively. Between these zones there is another zone where annual predicted generations range from 2 to 6 . In the Far East area 1 to 2 annual generations of Dirofilaria in most of the territory with a small zone with 2-6 annual generations are predicted. During the following two periods the boundary of the Southwestern area moved progressively until latitude $60^{\circ} \mathrm{N}$ in the European Northwestern side while it turned back slightly in Western Siberia. Both the zones with 2-6 and 6-12 predicted generations clearly extend to the Northwest. Scattered small areas with 1 to 2 predicted generations appear in Siberia as far as latitude $64^{\circ} \mathrm{N}$ (near the Polar Circle), along the Yenisei and Lena river basins, the Far East area remaining almost stable. Moreover, an altitudinal spreading also occurs, since some low lands of the Tien Shan/Pamir ranges become included in the predicted area. The increase of the area suitable for transmission $5.8 \%$ in 1991-2000 and 9\% in 2001-2011) is accompanied by rises in the estimated population exposure of $7 \%$ and $7.4 \%$, while person-year of exposure, respectively, rises 3.3\% and $14.3 \%$ in the same periods (Table 1). 


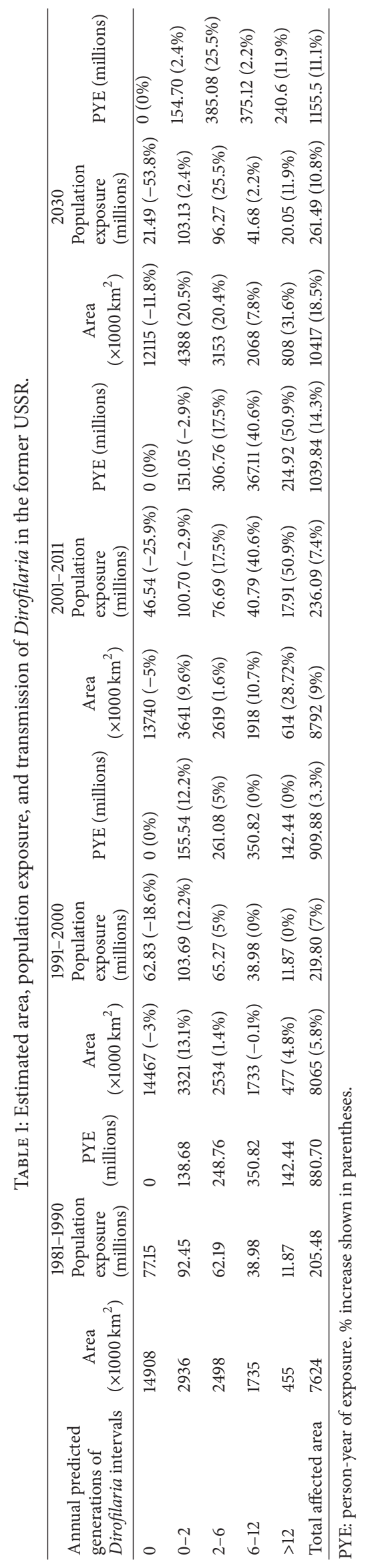




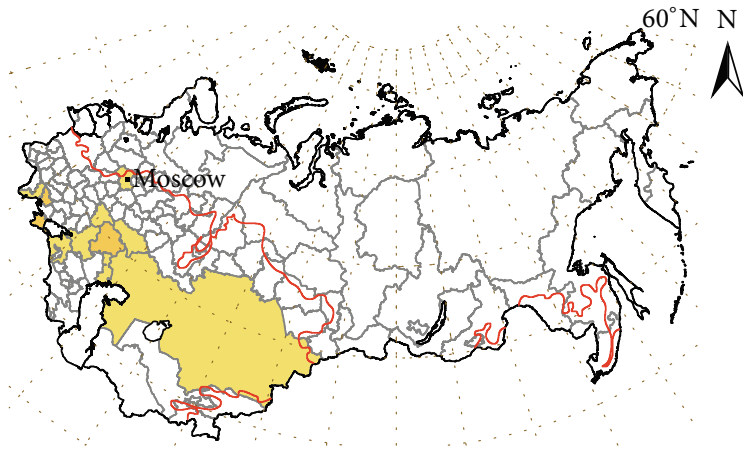

(a)

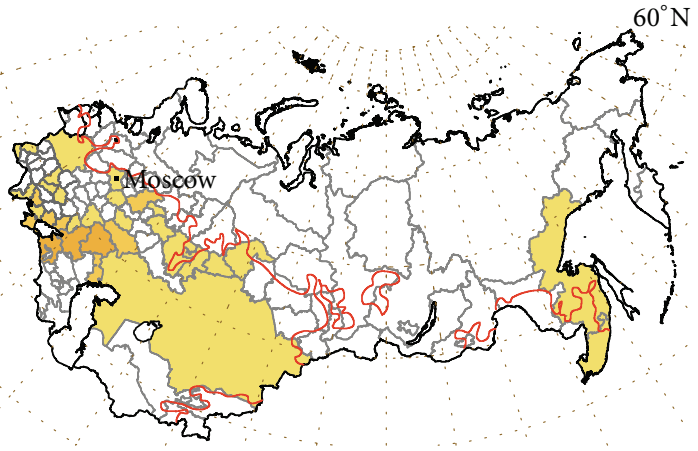

(b)

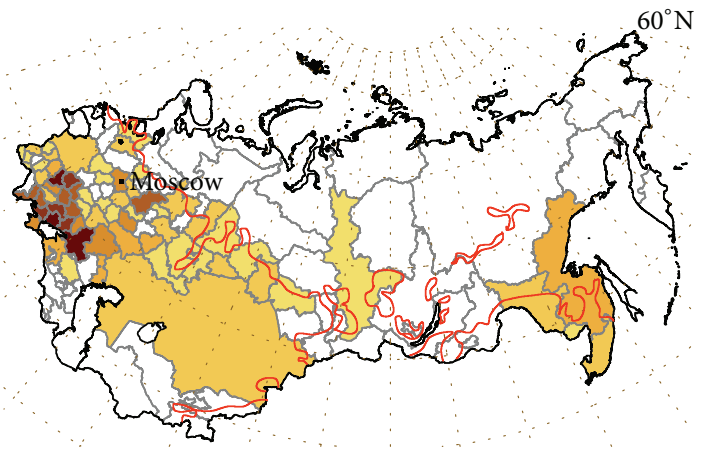

(c)
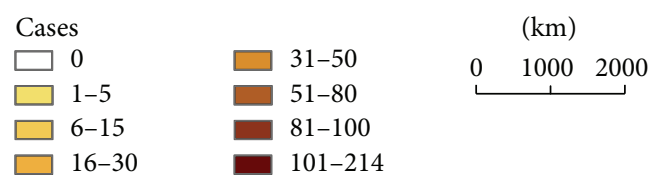

FIGURE 2: Administrative units of the former USSR where human dirofilariosis cases have been reported: 1981-1990 (a), 1991-2000 (b), and 2001-2011 (c). The red lines indicate the northern boundary of the predicted risk area of each lapse.

The retrospective review revealed 2154 cases of human dirofilariosis reported in the former USSR from 1981 to 2011. Data of geographical location, incidence, and morbidity are presented in Table 2. Fifty-eight, 196, and 1900 cases were, respectively, reported in 1981-1990, 1991-2000, and 2001-2011, most of them diagnosed in Ukraine and the Russian Federation. Cases appeared between latitudes $42^{\circ} \mathrm{N}$ (Kazakhstan) and $60^{\circ} \mathrm{N}$ (St. Petersburg) in 68 out of the 125 administrative units of the former USSR. Until 1996 there was a low annual incidence (2-11 cases/year), while from 1997 to 2011 incidence strongly rises from 22 to 365 cases/year. Morbidity rises over time in all administrative units where clinical cases have been referenced, except in Krasnodar (Southwestern Russia Federation), where reported cases decreased from 1991-2000 to 2001-2011 periods. Highest increases occurred in the Ukrainian and Russian administrative units near the Black and Azov seas, along the Dnieper, Don, and Volga river basins and in some regions of Southwestern Siberia. In relation to the validation of the model, the temporal and spatial distribution of cases reported in the literature review (by decades and administrative units) is shown in Figure 2. The concordance analysis between the predicted transmission areas and the spatiotemporal distribution of clinical cases shows that the model correctly predicts $97.10 \%$ of cases with a confidence interval (CI) of $92.42-100 \%$. By periods the concordances are, respectively, $100 \%$ with CI of $96.15-100 \%$, $96.97 \%$ with CI of $89.61-100 \%$, and $98.53 \%$ with CI of $94.93-100 \%$. The Pearson coefficient to assess the correlation between the number of predicted yearly generations and morbidity (Figure 3 ) shows a significant correlation at the global level $(0.560, P<0.01)$. By periods, correlations were 0.457 (1981-1990), 0.546 (19912000), and 0.510 (2001-2011), with $P<0.01$ in all cases. The analysis revealed the existence of exceptional situations in very few administrative units, where higher or lower morbidities than expected appeared. Comparative dynamics of yearly appearance of the threshold of 130 GDDs allowing extrinsic incubation and incidence of cases was assessed in Moscow, as representative of the administrative units close to the North boundary of predicted area (Figure 4). From 1981 to 2000 , when only 8 out of 20 years reached the threshold of 130 GDDs, 3 cases were recorded. From 2001 to 2011, with 8 out of 11 years reaching the threshold, 40 cases were reported in a yearly consecutive series. This series began after 4 consecutive years (1997-2000) reaching the threshold. 


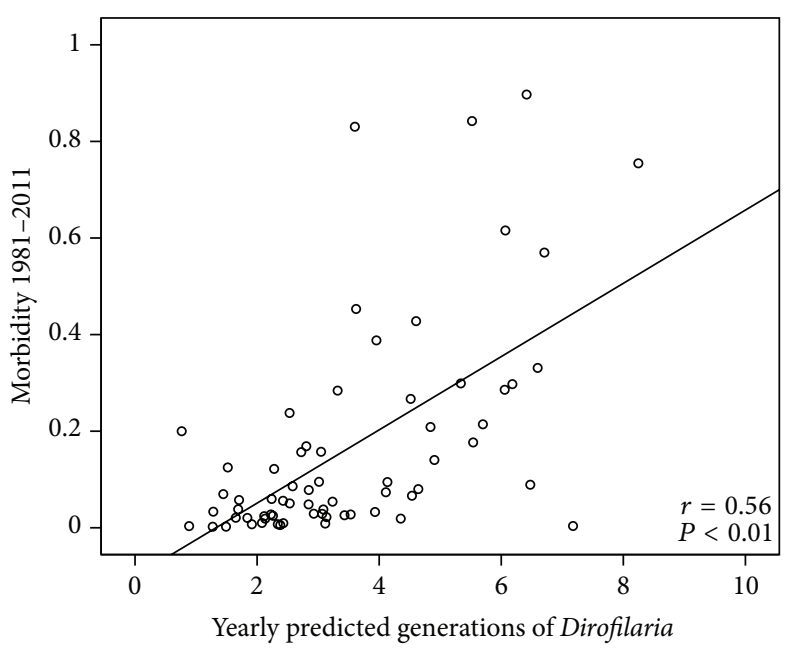

(a)

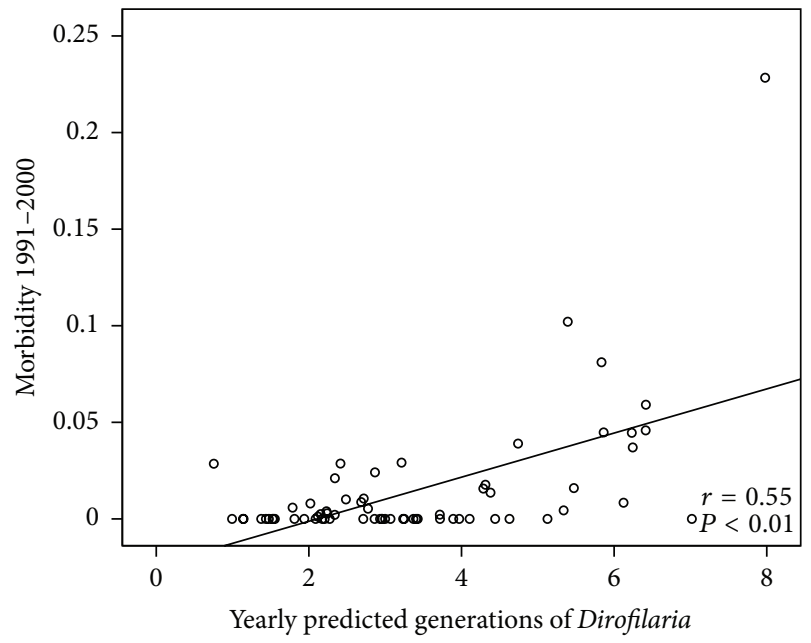

(c)

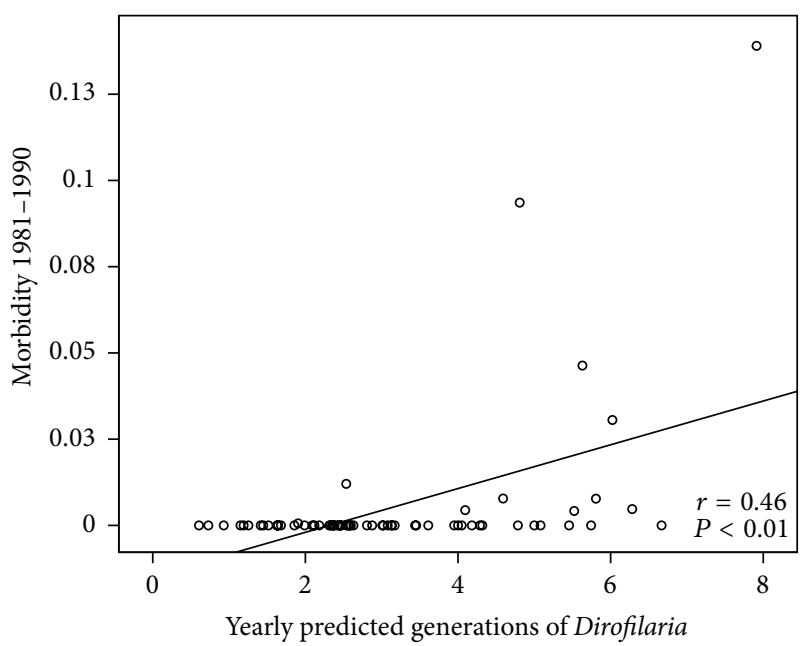

(b)

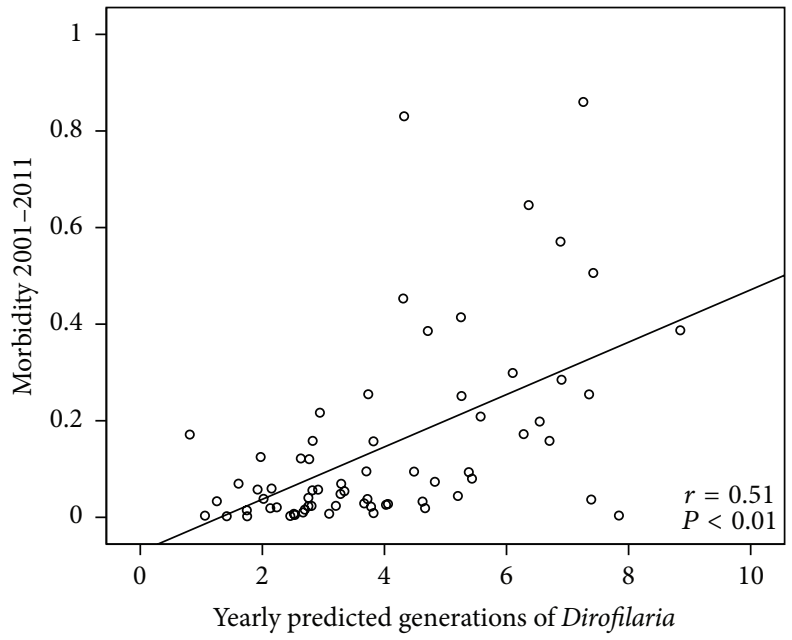

(d)

FiguRE 3: Statistical correlation (Pearson correlation coefficient) between yearly predicted generations of Dirofilaria and morbidity. From 1981 to 2011 (a), from 1981 to 1990 (b), from 1991 to 2000 (c), and from 2001 to 2011 (d).

Projection by 2030 (Figure 1(d)) predicts extensive latitudinal and altitudinal changes in the potential transmission area (18.5\% of surface area increase), with a $46 \%$ of the total territory and 110 out of 125 administrative units of the former USSR becoming included. These changes mainly occur in the northern zone with low number of predicted generations, the following being the most important: (1) the northward shift of the boundary exceeding latitude $60^{\circ} \mathrm{N}$ in all the Southwestern area; (2) the spreading of Siberian areas which have previously appeared; (3) the slight increase of the Far East area; (4) the continuing altitudinal spreading in low lands of the Urals and Tien Shan/Pamir ranges. Population exposure in 2030 will rise to $10.8 \%$, affecting $92.4 \%$ of the total former USSR population, while the person-year of exposure will increase $11.1 \%$, in respect of estimations of 2001-2011 period (Table 1).

\section{Discussion}

The effects of climatic change on the vector-borne diseases are greatest at the temperature range extremes at which transmission occurs $\left(14^{\circ}-18^{\circ} \mathrm{C}\right.$ and $\left.35^{\circ}-40^{\circ} \mathrm{C}\right)$ [27]. Thus, important modifications in the distribution and seasonality of these diseases in temperate and cold areas where changes occur are expected [3]. The former USSR can be considered a paradigm of this fact because of its vast size and climatic variety, the strong thermal anomalies observed there in the last years $[19,28]$, the current recognition of human dirofilariosis as an emerging disease $[14,15]$, and precedents which have already demonstrated the emergence of different zoonotic diseases in the Russian Arctic [29].

In the present work a spatiotemporal model, based on climatic forecast using the concept of growing degree days [16], retrospectively predicts a latitudinal and altitudinal spreading of the potential transmission area of Dirofilaria, mainly in the Russian Federation and Ukraine, near the boundaries where temperatures are close to the threshold for extrinsic incubation of parasite larvae. Moreover, strong increases in the population exposure and person-year of exposure are also predicted, as a consequence of both the spreading trends into highly populated zones and the rise 
TABLE 2: Reported cases and morbidity of human dirofilariosis in the former USSR. Morbidity is expressed as (number of cases/year/100000 habitants).

(a)

\begin{tabular}{|c|c|c|c|c|c|c|c|}
\hline & \multirow{2}{*}{ Population } & \multicolumn{2}{|c|}{ 1981-1990 } & \multicolumn{2}{|c|}{$1991-2000$} & \multicolumn{2}{|c|}{ 2001-2011 } \\
\hline & & Cases & Morbidity & Cases & Morbidity & Cases & Morbidity \\
\hline \multicolumn{8}{|l|}{ Russia } \\
\hline St-Petersburg & 4600276 & 0 & 0.000 & 0 & 0.000 & 1 & 0.002 \\
\hline Krasnoyarsk & 2893926 & 0 & 0.000 & 0 & 0.000 & 1 & 0.003 \\
\hline Perm & 2701174 & 0 & 0.000 & 0 & 0.000 & 9 & 0.033 \\
\hline Kirov & 1391059 & 0 & 0.000 & 0 & 0.000 & 8 & 0.058 \\
\hline Sverdlovsk & 4393797 & 0 & 0.000 & 0 & 0.000 & 1 & 0.002 \\
\hline Novgorod & 640613 & 0 & 0.000 & 0 & 0.000 & 8 & 0.125 \\
\hline Yaroslavl & 1306320 & 0 & 0.000 & 0 & 0.000 & 5 & 0.038 \\
\hline Tyumen & 3430313 & 0 & 0.000 & 2 & 0.006 & 5 & 0.015 \\
\hline Ivanovo & 1066541 & 0 & 0.000 & 0 & 0.000 & 13 & 0.122 \\
\hline Mari-El & 698176 & 0 & 0.000 & 2 & 0.029 & 4 & 0.057 \\
\hline Nizhni-Novgorod & 3323600 & 0 & 0.000 & 7 & 0.021 & 72 & 0.217 \\
\hline Omsk & 2012092 & 0 & 0.000 & 0 & 0.000 & 12 & 0.060 \\
\hline Vladimir & 1430084 & 0 & 0.000 & 0 & 0.000 & 8 & 0.056 \\
\hline Moscow & 17315765 & 1 & 0.001 & 2 & 0.001 & 40 & 0.023 \\
\hline Kurgan & 947566 & 0 & 0.000 & 1 & 0.011 & 15 & 0.158 \\
\hline Tatarstan & 3778504 & 0 & 0.000 & 2 & 0.005 & 9 & 0.024 \\
\hline Novosibirsk & 2649871 & 0 & 0.000 & 0 & 0.000 & 5 & 0.019 \\
\hline Smolensk & 965986 & 0 & 0.000 & 0 & 0.000 & 2 & 0.021 \\
\hline Khabarovsk & 1400425 & 0 & 0.000 & 4 & 0.029 & 24 & 0.171 \\
\hline Chelyabinsk & 3508447 & 0 & 0.000 & 1 & 0.003 & 1 & 0.003 \\
\hline Bashkortostan & 4065993 & 0 & 0.000 & 1 & 0.002 & 2 & 0.005 \\
\hline Kaluga & 1001559 & 0 & 0.000 & 0 & 0.000 & 1 & 0.010 \\
\hline Mordovia & 826526 & 0 & 0.000 & 0 & 0.000 & 4 & 0.048 \\
\hline Ryazan & 1151439 & 0 & 0.000 & 1 & 0.009 & 8 & 0.069 \\
\hline Amur & 860686 & 0 & 0.000 & 0 & 0.000 & 6 & 0.070 \\
\hline Samara & 3170141 & 0 & 0.000 & 0 & 0.000 & 30 & 0.095 \\
\hline Penza & 1373236 & 0 & 0.000 & 4 & 0.029 & 35 & 0.255 \\
\hline Altay & 2490714 & 3 & 0.012 & 6 & 0.024 & 30 & 0.120 \\
\hline Tambov & 1088437 & 0 & 0.000 & 0 & 0.000 & 3 & 0.028 \\
\hline Lipetsk & 1157852 & 0 & 0.000 & 0 & 0.000 & 3 & 0.026 \\
\hline Orenburg & 2112910 & 0 & 0.000 & 0 & 0.000 & 4 & 0.019 \\
\hline Saratov & 2564835 & 2 & 0.008 & 10 & 0.039 & 24 & 0.094 \\
\hline Kursk & 1148610 & 0 & 0.000 & 0 & 0.000 & 1 & 0.009 \\
\hline Voronezh & 2261628 & 1 & 0.004 & 4 & 0.018 & 10 & 0.044 \\
\hline Belgorod & 1530124 & 0 & 0.000 & 0 & 0.000 & 5 & 0.033 \\
\hline Volgograd & 2589887 & 12 & 0.046 & 21 & 0.081 & 41 & 0.158 \\
\hline Biribidzhan & 185039 & 0 & 0.000 & 0 & 0.000 & 1 & 0.054 \\
\hline Rostov & 4229505 & 2 & 0.005 & 27 & 0.064 & 214 & 0.506 \\
\hline Astrakhan & 1007113 & 14 & 0.139 & 23 & 0.228 & 39 & 0.387 \\
\hline Krasnodar & 5160656 & 4 & 0.008 & 23 & 0.045 & 19 & 0.037 \\
\hline Vladivostok & 1981970 & 0 & 0.000 & 2 & 0.010 & 8 & 0.040 \\
\hline Stavropol & 2711198 & 0 & 0.000 & 0 & 0.000 & 1 & 0.004 \\
\hline
\end{tabular}


(a) Continued.

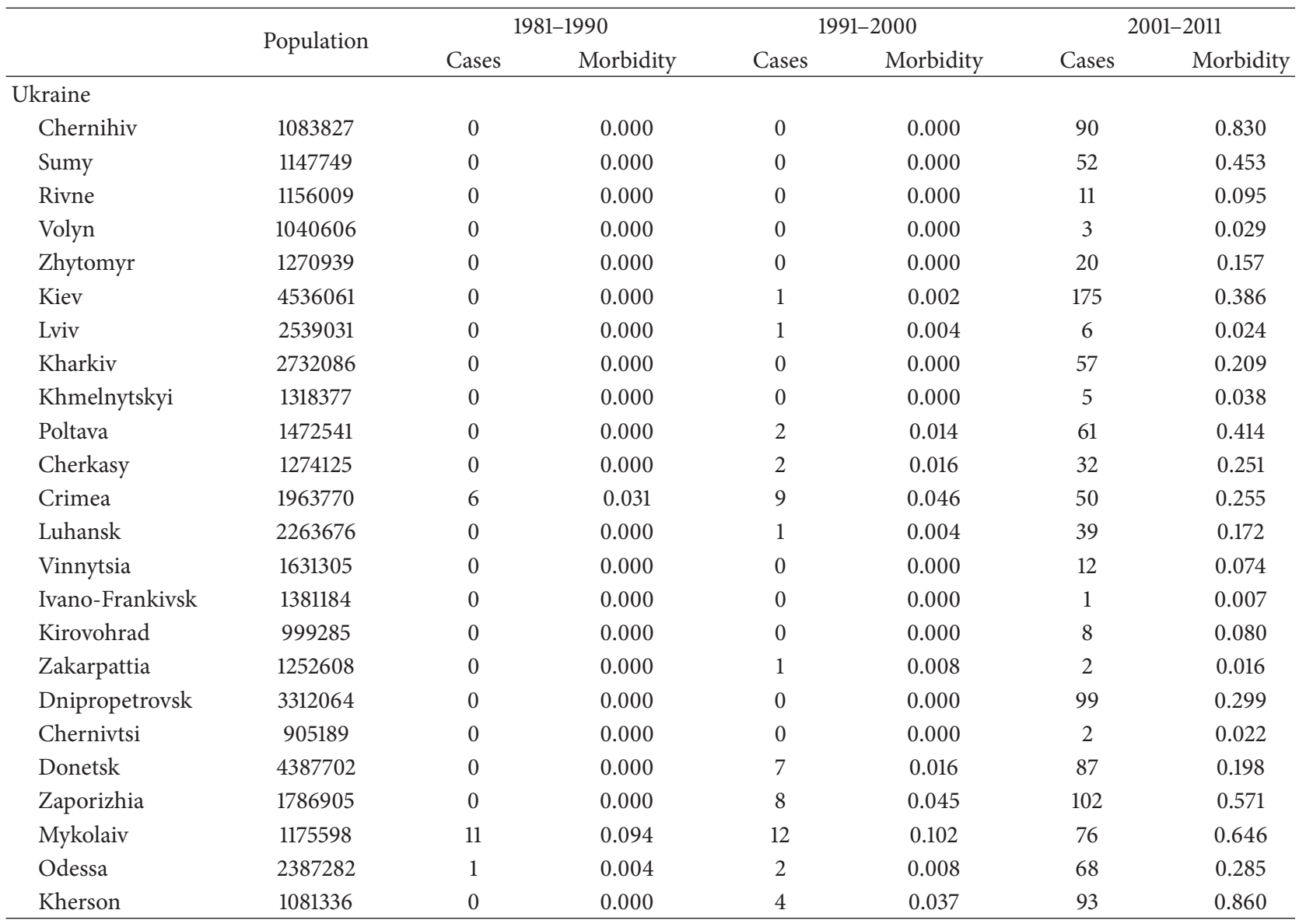

(b)

\begin{tabular}{|c|c|c|c|c|c|c|c|}
\hline \multirow{2}{*}{$\begin{array}{l}\text { Post-Soviet } \\
\text { states }\end{array}$} & \multirow{2}{*}{ Population } & \multicolumn{2}{|c|}{ 1981-1990 } & \multicolumn{2}{|c|}{ 1991-2000 } & \multicolumn{2}{|c|}{ 2001-2011 } \\
\hline & & Cases & Morbidity & Cases & Morbidity & Cases & Morbidity \\
\hline Belarus & 9457500 & 0 & 0.000 & 2 & 0.002 & 7 & 0.007 \\
\hline Kazakhstan & 16004800 & 1 & 0.001 & 1 & 0.001 & 10 & 0.006 \\
\hline
\end{tabular}

(c)

\begin{tabular}{lcccc}
\hline Total cases & $1981-1990$ & $1991-2000$ & $2001-2011$ & Total \\
\hline Russia & 39 & 143 & 732 & 914 \\
Ukraine & 18 & 50 & 1151 & 1219 \\
Post-Soviet states & 1 & 3 & 17 & 21 \\
USSR & 58 & 196 & 1900 & 2154 \\
\hline
\end{tabular}

of the predicted yearly generations in Southwestern zones where dirofilariosis was already endemic. One of the most important problems related to prediction models is their correct validation, due to the frequent lack of suitable tools $[17,30]$. To validate our model we used the clinical cases of human dirofilariosis identified by a retrospective review and derived morbidity in the studied territory from 1981 to 2011. In spite of clinical cases being only "the tip of the iceberg" of human dirofilariosis [31] their existence and dynamic of appearance can be good markers of the disease because, in endemic areas, human infections appear in parallel to canine dirofilariosis [32]. The retrospective review revealed that approximately $65 \%$ of the total cases of human dirofilariosis published in the world until 2011 were reported in the former USSR. Despite of this relatively abundant information, validation must be carefully analyzed. There exists a very high congruence between the transmission areas predicted by the model and the real spatiotemporal distribution of cases reported between 1981 and 2011 that confirms the spreading trend of the disease towards the Northwest of the area studied. Moreover, a significant statistical correlation between the number of annual predicted generations and morbidity exists. Nevertheless, there are some exceptions to the concordances observed, like the higher morbidity than 


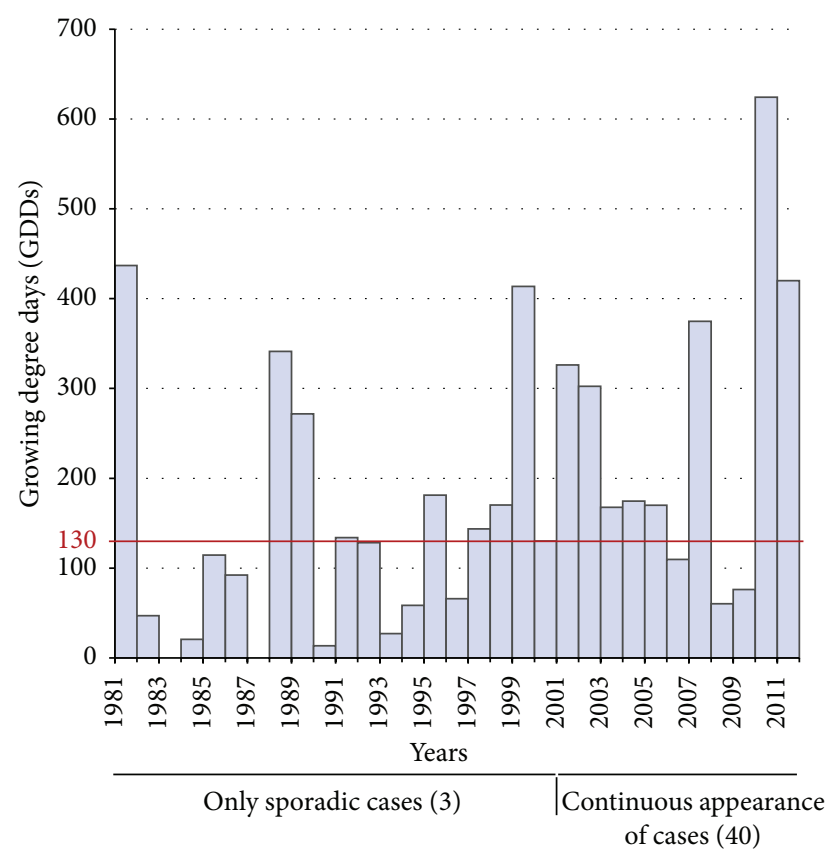

Figure 4: Appearance dynamics of human dirofilariosis cases and GDDs in Moscow administrative unit.

expected in some Ukrainian and neighboring Russian administrative units and the lower morbidity than expected in some other Russian administrative units and Southern Asian republics. In the first case the situation can be attributed both to appropriate conditions for transmission and the awareness and wide experience of physicians in the differential diagnosis of the disease, which has led to numerous case reports. Moreover, human dirofilariosis is a notifiable disease from 1997 in Ukraine, a fact making these data very reliable. Otherwise, Asian republics have a very low hydrothermal coefficient (less than 1) [24] limiting the development of mosquito populations in most of their territory, which consist mainly of populated areas concentrated near the water bodies. Moreover, human dirofilariosis is not habitually included in the differential diagnosis of subcutaneous or pulmonary nodules in these countries. As a consequence, in spite of the high number of predicted generations of Dirofilaria, human cases are detected sporadically, but they will probably emerge when they become appropriately diagnosed, near the water bodies. Spreading of human dirofilariosis along the Dnieper, Don, and Volga river basins is consistent with the need of humidity as a key factor related to the abundance of mosquito populations. This fact also appears in the spreading predicted in Siberia where new risk areas emerge along the Yenisei and Lena river basins.

Emergence of human dirofilariosis in administrative units located closer to the northern boundary of the predicted area could be delayed in respect to the real introduction time, since consecutive appearance of cases seems to occur only after some years consecutively reaching the threshold allowing extrinsic incubation, as has been observed in Moscow. Otherwise morbidity rises have been detected between 2001 and 2011 in this and other administrative units near the northern boundary (see Table 2). Taken together, these two facts suggest that in spite of the apparent slow emergence of human dirofilariosis when suitable conditions for transmission occur sporadically or during short periods of time, once introduced and with suitable conditions, the disease can present a strong spreading potential.

Projection by 2030 maintains the geographical spreading pattern shown retrospectively by the model as well as the increase in the person-year of exposure, which occurs mainly in zones of the Southwestern area where 2-6 annual predicted generations are predicted. These predictions are consistent with the increase in temperatures foreseen by that time by the Russian Committee of Hydrometeorology. This agency predicts more moderate thermal increases than other organisms; thus, different scenarios could be taken in consideration. With these findings we can assume that human dirofilariosis morbidity will increase in the future, emerging in many northern cold administrative units of the European Russia, in low lands of the ranges and in Siberia as far as latitude $64^{\circ} \mathrm{N}$. Moreover, morbidity will strongly increase in Southwestern zones with medium number of predicted yearly generations.

\section{Conclusion}

Our model suggests that regional warming is clearly associated with the long-term spreading and emergence of dirofilariosis in extensive territories of the former USSR confirmed by the spatiotemporal appearance pattern of cases from 1981 to 2011. Nevertheless, factors influencing the dynamic of vectorborne diseases are complex, so prediction models necessarily must simplify the real situation. Our analysis suggests the involvement of other factors not included in the model like humidity, population distribution, knowledge of and interest in the disease by the scientific community, and probably pets management (there is a huge stray dogs population lacking preventive measures in the former USSR acting as reservoirs), among others. Our findings, together with the demonstrated severity of many cases, suggest that human dirofilariosis has become a serious medical problem that will increase in the future; thus, control of reservoir infections is urgently needed. Our model can help to design appropriate preventive and control strategies in the post-Soviet states. Moreover, these results can alert about the epidemiological behavior of this and other mosquito-borne diseases, not analyzed until now in different areas of the world.

\section{Conflict of Interests}

The authors declare that there is no conflict of interests regarding the publication of this paper.

\section{Authors' Contribution}

Vladimir Kartashev performed the retrospective review. Alexandr Afonin and Luis Simón developed the GIS model. Rosa Sepúlveda conducted the statistical analyses. Javier González-Miguel, Rodrigo Morchón, and Fernando Simón processed and analyzed the data. Javier González-Miguel 
and Fernando Simón wrote and organized the paper. Fernando Simón designed the project. All authors approved the final version of the paper.

\section{Acknowledgments}

The authors thank Dr. Pavlikovskaya for allowing them access to the archives of the Ukranian Ministry of Health, Dr. Mar Siles-Lucas for the critical review of the paper, and Alfredo Moro-Martín for language corrections. Financial support was obtained from the Regional Government of Castilla-León and Saint-Petersburg State University (grant 0.37.526.2013).

\section{References}

[1] IPCC, "Climate change 2007: synthesis report," in Contribution of Working Groups I, II and III to the Fourth Assessment Report of the Intergovernmental Panel on Climate Change, Core Writing Team, R. K. Pachauri, and A. Reisinger, Eds., p. 104, IPCC, Geneva, Switzerland, 2007.

[2] A. J. McMichael, R. E. Woodruff, and S. Hales, "Climate change and human health: present and future risks," The Lancet, vol. 367, no. 9513, pp. 859-869, 2006.

[3] J. C. Semenza and B. Menne, "Climate change and infectious diseases in Europe," The Lancet Infectious Diseases, vol. 9, no. 6, pp. 365-375, 2009.

[4] EASAC, "Climate change and infectious diseases in Europe," c2010, http://www.easac.eu/home/reports-and-statements/ detail-view/article/climate-chan.html.

[5] F. Simón, M. Siles-Lucas, R. Morchón et al., "Human and animal dirofilariasis: the emergence of a zoonotic mosaic," Clinical Microbiology Reviews, vol. 25, no. 3, pp. 507-544, 2012.

[6] J. W. McCall, C. Genchi, L. H. Kramer, J. Guerrero, and L. Venco, "Chapter 4 heartworm disease in animals and humans," Advances in Parasitology, vol. 66, pp. 193-285, 2008.

[7] F. Simón, R. Morchón, J. González-Miguel, C. Marcos-Atxutegi, and M. Siles-Lucas, "What is new about animal and human dirofilariosis?" Trends in Parasitology, vol. 25, no. 9, pp. 404409, 2009.

[8] T. I. Avdiukhina, A. I. Lysenko, V. G. Supriaga, and V. F. Postnova, "Dirofilariasis of the vision organ: registry and analysis of 50 cases in the Russian Federation and in countries of the United Independent States," Vestnik oftalmologii, vol. 112, no. 3, pp. 35-39, 1996 (Russian).

[9] C. Genchi, L. H. Kramer, and F. Rivasi, "Dirofilarial infections in Europe," Vector-Borne and Zoonotic Diseases, vol. 11, no. 10, pp. 1307-1317, 2011.

[10] J. Y. Ro, P. J. Tsakalakis, V. A. White et al., "Pulmonary dirofilariasis: the great imitator of primary or metastatic lung tumor. A clinicopathologic analysis of seven cases and a review of the literature," Human Pathology, vol. 20, no. 1, pp. 69-76, 1989.

[11] B. Ilyasov, V. Kartashev, N. Bastrikov, R. Morchón, J. GonzálezMiguel, and F. Simón, "Delayed diagnosis of dirofilariasis and complex ocular surgery, Russia," Emerging Infectious Diseases, vol. 19, no. 2, pp. 326-327, 2013.

[12] C. Genchi, L. H. Kramer, and G. Prieto, "Epidemiology of canine and feline dirofilariasis: a global view," in Heartworm Infection in Humans and Animals, F. Simón and C. Genchi, Eds., pp. 121-134, Ediciones Universidad de Salamanca, Salamanca, Spain, 2001.
[13] S. Pampiglione and F. Rivasi, "Human dirofilariasis to Dirofilaria (Nochtiella) repens: an update of world literature from 1995-2000," in Dirofilaria Immitis and D. Repens in Dog and Cat and Human Infections, C. Genchi, L. Rinaldi, and G. Cringoli, Eds., pp. 83-116, Rolando Editore, Naples, Italy, 2007.

[14] L. H. Kramer, V. V. Kartashev, G. Grandi et al., "Human subcutaneous dirofilariasis, Russia," Emerging Infectious Diseases, vol. 13, no. 1, pp. 150-152, 2007.

[15] V. Kartashev, I. Batashova, S. Kartashov et al., "Canine and human dirofilariosis in the Rostov Region (Southern Russia)," Veterinary Medicine International, vol. 2011, Article ID 685713, 5 pages, 2011.

[16] L. Rinaldi, V. Musella, A. Biggeri, and G. Cringoli, "New insights into the application of geographical information systems and remote sensing in veterinary parasitology," Geospatial Health, vol. 1, no. 1, pp. 33-47, 2006.

[17] F. C. Tanser, B. Sharp, and D. Le Sueur, "Potential effect of climate change on malaria transmission in Africa," The Lancet, vol. 362, no. 9398, pp. 1792-1798, 2003.

[18] C. Genchi, L. Rinaldi, M. Mortarino, M. Genchi, and G. Cringoli, "Climate and Dirofilaria infection in Europe," Veterinary Parasitology, vol. 163, no. 4, pp. 286-292, 2009.

[19] National oceanic and atmospheric administration (NOAA) [Internet]. United States Department of Commerce, c2013, http://www.noaa.gov/.

[20] Federal Service for Hydrometeorology and Environmental Monitoring, Evaluation Report on Climate Change and Its Impact on the Russian Federation, Federal Service for Hydrometeorology and Environmental Monitoring, Moscow, Russia, 2008.

[21] J. F. Fortin and J. O. D. Slocombe, “Temperature requirements for the development of Dirofilaria immitis in Aedes triseriatus and Ae. vexans," Mosquito News, vol. 41, pp. 625-633, 1981.

[22] J. B. Lok and D. H. Knight, "Laboratory verification of a seasonal heartworm transmission model," in Proceedings of the Recent Advances in Heartworm Disease Symposium '98, R. L. Seward and D. H. Knight, Eds., pp. 15-20, American Heartworm Society, Batavia, NY, USA, 1998.

[23] S. L. Greene, T. C. Hart, and A. Afonin, "Using geographic information to acquire wild crop germplasm for ex situ collections: I. Map development and field use," Crop Science, vol. 39, no. 3, pp. 836-842, 1999.

[24] A. N. Afonin, S. L. Greene, N. I. Dzyubenko, and A. N. Frolov, Interactive Agricultural Ecological Atlas of Russia and Neighboring Countries. Economic Plants and their Diseases, Pests and Weeds. 2008, http://www.agroatlas.ru/.

[25] L. Simón, A. Afonin, L. I. López-Díez et al., "Geo-environmental model for the prediction of potential transmission risk of Dirofilaria in an area with dry climate and extensive irrigated crops. The case of Spain," Veterinary Parasitology, vol. 200, no. 3-4, pp. 257-264, 2014.

[26] A. Jarvis, H. I. Reuter, A. Nelson, and E. Guevara, Hole-filled SRTM for the globe Version 4. [Internet] c2008 [updated 2014 May 21; cited 2014 May 21]. Available from the CGIAR-CSI SRTM 90m Database, http://srtm.csi.cgiar.org/.

[27] A. K. Githeko, S. W. Lindsay, U. E. Confalonieri, and J. A. Patz, "Climate change and vector-borne diseases: a regional analysis," Bulletin of the World Health Organization, vol. 78, no. 9, pp. 1136-1147, 2000.

[28] Berkeley Earth, A Measured Approach: Climate Science + Strategic Analysis, c2013, http://Berkeleyearth.org/. 
[29] B. Revich, N. Tokarevich, and A. J. Parkinson, "Climate change and zoonotic infections in the Russian Arctic," International Journal of Circumpolar Health, vol. 71, p. 18792, 2012.

[30] J. C. Semenza, J. E. Suk, V. Estevez, K. L. Ebi, and E. Lindgren, "Mapping climate change vulnerabilities to infectious diseases in Europe," Environmental Health Perspectives, vol. 120, no. 3, pp. 385-392, 2012.

[31] F. Simón, J. López-Belmonte, C. Marcos-Atxutegi, R. Morchón, and J. R. Martín-Pacho, "What is happening outside North America regarding human dirofilariasis?" Veterinary Parasitology, vol. 133, no. 2-3, pp. 181-189, 2005.

[32] J. A. Montoya-Alonso, I. Mellado, E. Carretón, E. D. CabreraPedrero, R. Morchón, and F. Simón, "Canine dirofilariosis caused by Dirofilaria immitis is a risk factor for the human population on the island of Gran Canaria, Canary Islands, Spain," Parasitology Research, vol. 107, no. 5, pp. 1265-1269, 2010. 


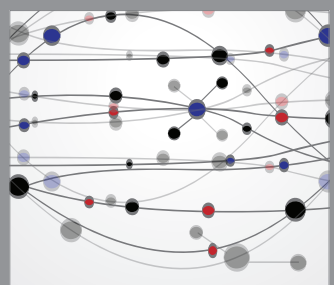

The Scientific World Journal
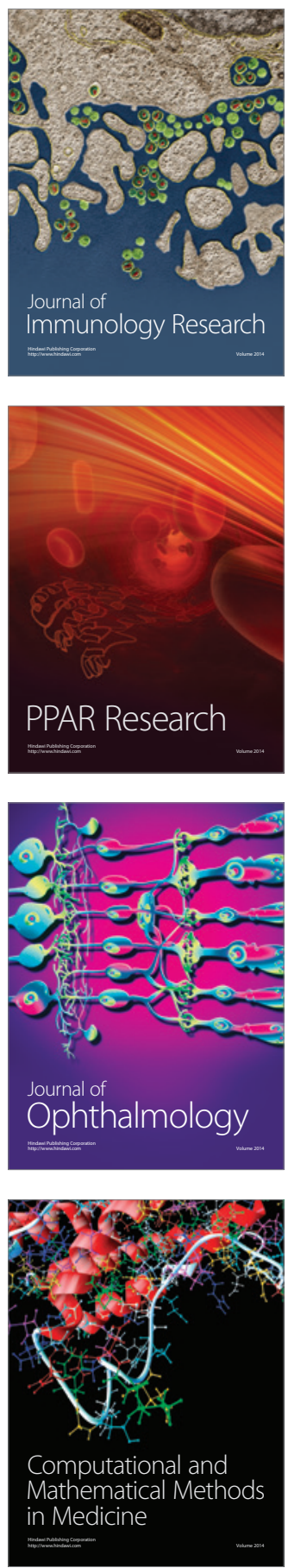

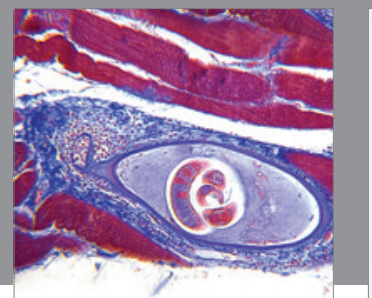

Gastroenterology

Research and Practice
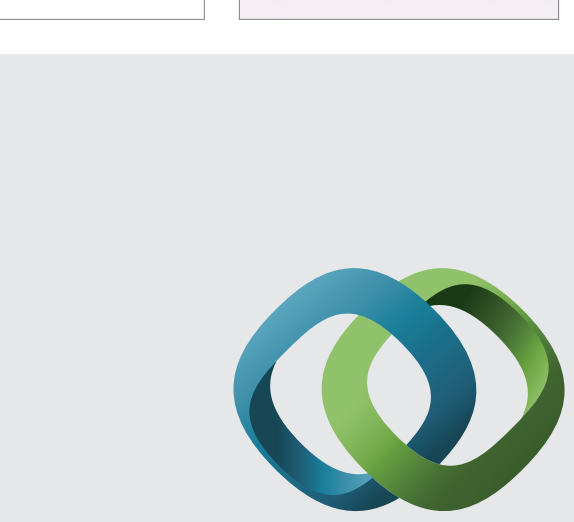

\section{Hindawi}

Submit your manuscripts at

http://www.hindawi.com
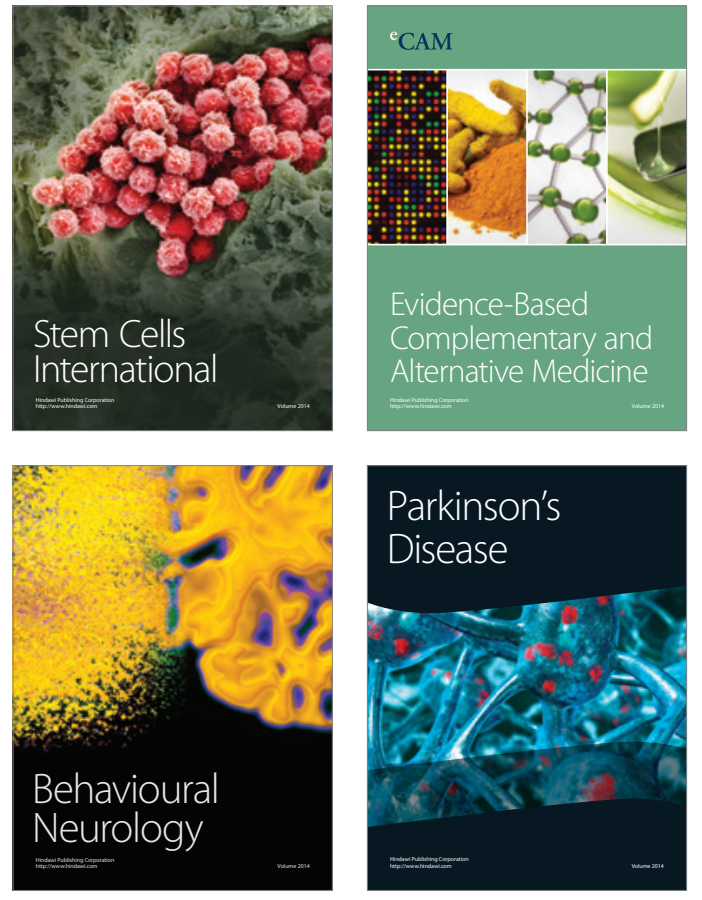
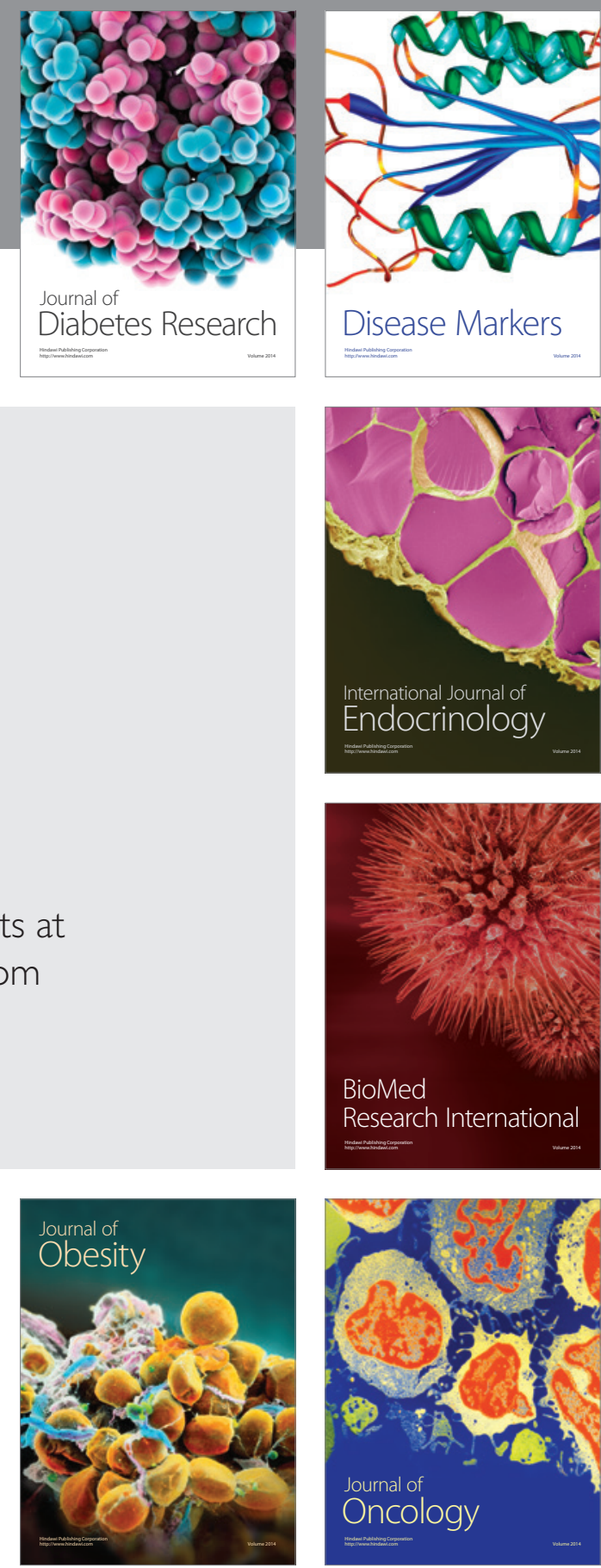

Disease Markers
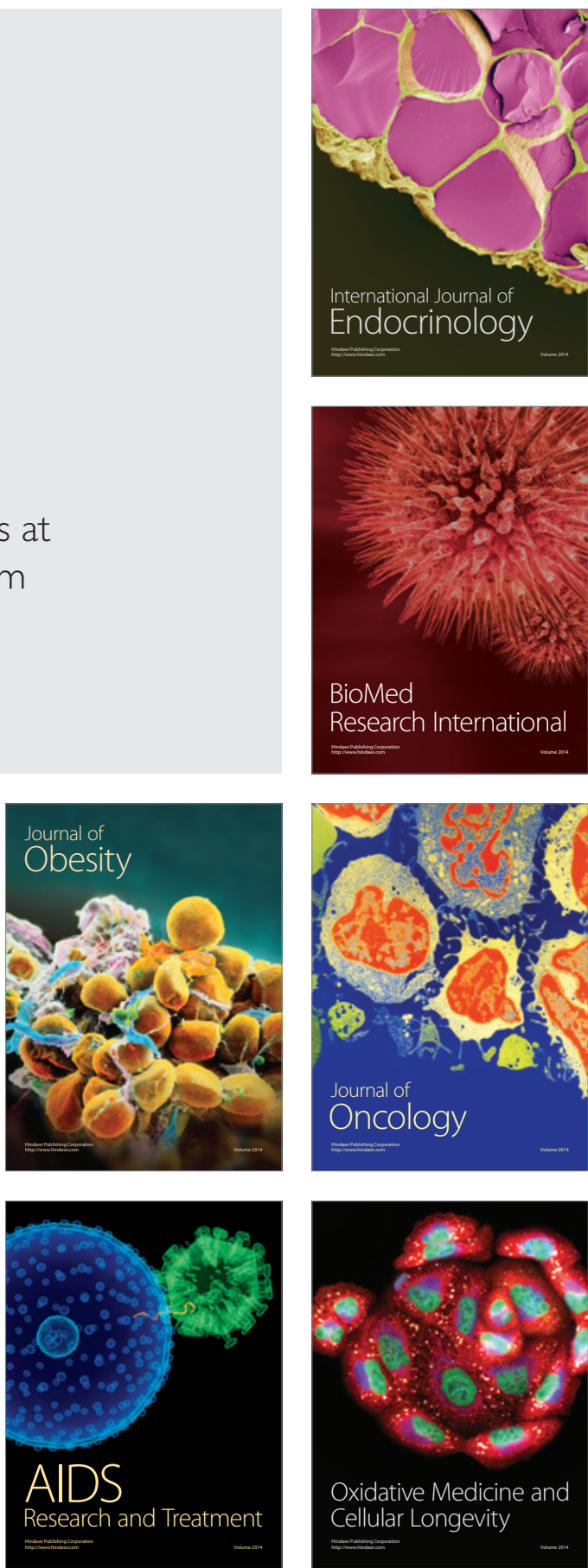